\title{
Discontinuation of modern contraception methods due to side effects and method failure in India: an analysis using reproductive calendar data
}

\author{
Mahesh R. Shete ${ }^{1}$, Prakash Kumar', Enu Anand", \\ Jayakant Singh ${ }^{2}$, Manas Ranjan Pradhan ${ }^{3 *}$
}

${ }^{1}$ International Institute for Population Sciences, Mumbai, Maharashtra, India

${ }^{2}$ School of Health Systems Studies, Tata Institute of Social Sciences, Mumbai, Maharashtra, India

${ }^{3}$ Department of Fertility Studies, International Institute for Population Sciences (IIPS), Mumbai, Maharashtra, India

Received: 09 July 2021

Revised: 06 August 2021

Accepted: 07 August 2021

\section{*Correspondence:}

Manas Ranjan Pradhan,

E-mail: manasiips@gmail.com

Copyright: () the author(s), publisher and licensee Medip Academy. This is an open-access article distributed under the terms of the Creative Commons Attribution Non-Commercial License, which permits unrestricted non-commercial use, distribution, and reproduction in any medium, provided the original work is properly cited.

\section{ABSTRACT}

Background: Contraceptive discontinuation for reasons other than the desire to get pregnant is a significant public health concern. This study aimed to understand the elaborated role of side effects and method failure behind modern reversible contraception method discontinuation among married women aged 15-49 years in India.

Methods: The analysis was based on 142992 episodes of contraceptive use contributed by 90414 married women aged 15-49 years covered in the National family health survey-4 (2015-2016). Multivariate analyses, discontinuation rates using the multiple/single decrement life table and multi-level multinomial competing risk analyses were performed.

Results: Discontinuation rate due to side effects within 12 months of use was highest for injectables (14.7\%) and lowest for male condoms (3\%) and due to method failure, it was highest for male condoms (3\%) and lowest among IUD users (1.2\%). Compared to women using IUD, those using pills had 2.3 times and 1.6 times the higher hazard of discontinuation due to method failure and side effects, respectively.

Conclusions: The discontinuation rate of all selected methods was higher due to side effects than method failure. The high discontinuation rate of many contraceptive methods and the frequency of contraceptive failure suggest the need for strategies to promote improved contraceptive use following method selection. Improved quality of services through proper counselling of the potential contraceptive users would enhance informed choice, thus increasing modern contraception continuation among women in India.

Keywords: Modern methods, Contraceptive discontinuation, Side effect, Method failure, India

\section{INTRODUCTION}

Contraception behaviour dynamics has obvious linkages with fertility control and optimal population size. As a medium for accelerating economic development, slow population growth has been the underlying premise of most family planning programmes worldwide, including in India. Several strides were made in family planning approaches including the quality of care and family planning as the population's rights in the last 2 decades. ${ }^{1-3}$ However, the progress in meeting contraceptive needs remains slow. Globally, the prevalence of contraceptive use has increased only by 10 per cent ( 54 to $64 \%$ ) in the last two decades. ${ }^{4,5}$ In fact, in a populous country like India, contraceptive prevalence shows a stagnated or declining trend. Several parameters such as couple protection rate, unmet need for family planning, the prevalence of reversible and irreversible family planning 
methods reflect the progress of the family planning programme. However, by far, the unmet need for family planning and the ability to use contraception continuously without discomfort are some of the critical goals of quality family planning services. ${ }^{2,6-11}$ Contraceptive discontinuation for reasons other than the desire to become pregnant results in millions of women having an unmet need for contraception. To a large extent, unintended pregnancies are an outcome of contraception discontinuation. ${ }^{12-18}$ An analysis using the demographic and health survey (DHS) data for 36 countries revealed that contraceptive discontinuation accounted for about one-third of total unintended births in all countries together. ${ }^{19}$ Moreover, contraceptive discontinuation is associated with an increased rate of induced abortions. ${ }^{16,18,20,21}$

Considering India as the second most populous country globally with an accelerating rate of population momentum, a further decline in fertility level depends much upon the consistent, correct and effective use of contraception $\cdot{ }^{17}$ Evidence indicated that ensuring access to contraception and providing the users with their preferred methods of contraception results in a high rate of contraceptive continuation. ${ }^{22}$ The discontinuation rates were far less among women who received information and counselling than those who did not. ${ }^{23}$ Contraceptive discontinuation due to reasons other than the desire to get pregnant was an important public health concern. The major two reasons attributed to the discontinuation of the reversible contraceptive method included side effects/health concerns and method failure, which negatively affected women's reproductive health. ${ }^{24}$ The effectiveness of any contraception can be assessed through its failure rate and almost negligible side effects. The methods with a high probability of failure cannot be promoted because it is a grave violation of women's reproductive rights as method failure directly lead to the burden of unwanted pregnancy among women. Harmful and health effect of any contraception depends on the level of side effects it poses to the women. Both these factors can be reduced through technological advancement and a method with the least side effects and minimum chances of method failure should be promoted at the policy and programme level.

This study, therefore, aimed to understand the elaborated role of side effects and method failure behind modern reversible contraception method discontinuation among women from various socio-economic and demographic characteristics. Since contraceptive prevalence alone did not provide a clear picture of contraceptive behaviour instead, consistent use, switching of methods, contraception failure, therefore, reproductive calendar data was used to examine underlying factors for contraceptive discontinuation. In this study, an estimation of the moderncontraceptive discontinuation rate is provided, spanning over a time frame of 60 months disaggregated by each year.

\section{METHODS}

\section{Study type}

The cross-sectional study data of the contraceptive use from the fourth round of the NFHS (2015-2016) was used in this study. Specifically, the study used the five years of retrospective calendar data from the NFHS- 4 .

\section{Study place}

The NFHS-4 is a nationally representative sample survey covering all the states and Union Territories. The sample included in this study thus represented India.

\section{Study period}

The data collection under the NFHS-4 survey was completed from January 2015 to December 2016.

\section{Sample selection criteria}

The survey used a multi-stage stratified sampling method to select the households and eligible women for interviews.

\section{Procedure}

In the survey, information was collected from evermarried women and never-married women aged 15-49 years and men aged 15-54 years. A detailed history of contraceptive use during the past five years was collected from the survey participants. NFHS-4 collected information from 601,509 households, with 699,686 eligible women aged 15-49 years. The details of the sampling design and implementation of the survey can be obtained from the all India NFHS-4 report (International institute for population sciences (IIPS) and ICF, 2017). The history of contraceptive methods used by women were collected through a reproductive calendar that recorded monthly contraceptive/pregnancy status for the five calendar years preceding the survey.

\section{Ethical approval}

Ethical approval was taken and only those respondents who voluntarily gave consent were interviewed in the survey. The data used in this paper is available in the public domain for research purposes.

\section{Statistical analysis}

The unit of analysis was the episodes of discontinued contraceptive methods among married women aged 15-49 years and not the women themselves. An episode of the use of contraception was defined as a consequent month or series of months during which a woman was using a contraceptive method. Since the analysis involved a history of use for the past five years, hence a woman may contribute more than one episode of any contraceptive 
method in the analysis if she switched from one method to another or used the same method after an interval of a month(s). The episodes starting in the 3-62 months prior to the survey were included in the analysis and those beyond this range were excluded. Since female sterilisation was considered a permanent or irreversible contraceptive method and sterilised women were less likely to use any other method except condoms in some instances, therefore, the episodes of female sterilisation were also excluded from the analysis. In total, the analysis was conducted using 93,902 episodes contributed by 60857 married women aged 15-49 years.

\section{Bio-demographic variables}

Bio-demographic characteristics used in this study to understand the background of contraceptive discontinuation included current age of women (15-19 years, 20-24 years, 25-29 years, 30-34 years, 35-39 years, 40-44 years, 45-49 years) and parity of the women (no child born (parity 0), one child (parity 1), two children (parity 2), three or more children ever born (parity 3+)). A variable named contraceptive intent was constructed using the information about the planning status (birth interval) of births. In the survey, all women were asked: whether the birth was wanted at that time, wanted later or not wanted at all. If a woman reported that the birth was wanted at that time or wanted later and was using the contraceptive method, then the contraceptive intent for that segment was classified as spacer, as they were using the contraception to have a gap between two births. If it was reported as not wanted at all and were using the contraceptive method, then the intent for that segment was classified as limiter, as they were using the contraceptive method to limit childbirth.

\section{Socio-economic variables}

Socio-economic variables used in the study included place of residence (urban-rural), religion (Hindu, Muslim, Christian, Sikh, others including Buddhist/Neo Buddhist, Jain and others), caste (scheduled caste-SC/scheduled tribe-ST, other backward classes-OBCs, others), education (no education, primary, secondary, higher secondary and above), mass media exposure (no, yes), wealth index (poorest, poorer, middle, richer, richest) and region (north, central, west, east, north-east, south).

\section{Contraceptive methods}

Discontinuation of selected modern methods of contraception was examined. The modern method included were injectables, intrauterine devices (IUDs/PPIUDs), contraceptive pills and male condoms.

\section{Reasons for discontinuation}

The survey recorded 20 reasons for discontinuation in the reproductive calendar history. However, for analytical reasons from policy and program point of view, only two prominent reasons for discontinuation were considered: contraceptive method failure (became pregnant while using) and side effect/health concern (side effect, health concerns, gained weight and created menstrual problem).

The unit of analysis was episodes of contraceptive methods used among married women aged 15-49 years. Descriptive statistics and bivariate analysis were performed to describe the context. Discontinuation rates of the contraceptive method were calculated using the multiple/single decrement life table and multinomial competing risk analyses. Using the single decrement life table approach, the life table gross rates were calculated for comparisons across subgroups, whereas the multiple decrement life-table method was used to calculate the net rates and model the observed dependent rates. ${ }^{26}$

A woman may discontinue the contraceptive method due to various reasons at any point in time; therefore, such data was often described as competing risks data. Hence, to understand the relationship between contraceptive discontinuation with selected socio-economic correlates, competing risk regression was used over the multinomial or cox-proportional hazard model. If an individual was at risk due to exposure to more than one cause for failure, the use of classical survival methods was not appropriate to analyse the time-to-event data. ${ }^{27}$ In the case of competing time-to-event data, the cumulative incidence function (CIF), which was the marginal probability of each competing event and was defined as the probability of individuals who developed the event of interest, regardless of if they were censored or failed from other competing events. According to Davis and Lawrance (1989), CIF was calculated as a product of two estimates: the estimate of hazard at ordered failure time $t_{f}$ for the event of interest expressed as,

$\hat{h}_{c}\left(t_{f}\right)=\frac{m_{c f}}{n_{f}}$

where,

$\mathrm{m}_{\mathrm{cf}}$ denotes the number of events for risk $\mathrm{c}$ at time,

$t_{f}$ and $n_{f}$ is the number of subjects at that time.

And the estimate of overall probability of surviving previous time,

$t_{(d-1)}: \hat{\mathrm{S}}\left(t_{f-1}\right)$,

where,

$\mathrm{S}_{\mathrm{t}}$ denotes the overall survival function rather than the cause specific survival function,

therefore, the incidence probability of failing from an event $\mathrm{c}$ at time $\mathrm{t}_{\mathrm{f}}$ can be estimated,

$\hat{I}_{c}\left(t_{f}\right)=\hat{S}\left(t_{f-1}\right) \times \hat{h}_{c}\left(t_{f}\right)$. 
Then, the CIF for event $\mathrm{c}$ at time $\mathrm{t}_{\mathrm{f}}$ is the cumulative sum up of incidence probabilities over all event $\mathrm{c}$ failure times, and is expressed as,

$$
\operatorname{CIF}_{c}\left(t_{f}\right)=\sum_{f^{\prime}=1}^{f} \hat{I}_{c}\left(t_{f}\right)=\sum_{f^{\prime}=1}^{f} \hat{S}\left(t_{f^{\prime}-1}\right) \times \hat{h}_{c}\left(t_{f^{\prime}}\right) .
$$

In a study, Fine et al 1999 proposed a proportional hazards function to model the CIF with covariates accounting for all the previously occurred event, including competing events, by considering the CIF curve as a sub-distribution function and expressed as, ${ }^{28}$

$$
\begin{aligned}
& h_{c, C I F}(t) \\
& =\lim _{\Delta \rightarrow 0} \frac{\operatorname{Pr}\left(t<T_{c}<t+\Delta t \mid T_{c}>t \cup T_{c^{\prime}} \leq t, c^{\prime} \neq c\right)}{\Delta t}
\end{aligned}
$$

Therefore, the CIF based proportional hazard model is defined as,

$$
h_{c, C I F}(t)=h_{0 c, C I F}(\exp )\left[\sum_{i=1}^{P} \gamma_{i} X_{i}\right]
$$

Unlike classical survival methods like the proportional hazard model, CIF does not disregard other competing risks while analysing a specific cause of interest. Therefore, in the present study, CIF based survival regression model had been used to examine the potential socio-economic risk factors of modern contraception discontinuation.

\section{RESULTS}

\section{Gross life-table cumulative discontinuation rate}

Of the total contraceptive episodes analysed $(93,902)$, half of the episodes' used were accounted for by male condoms (50\%) followed by contraceptive pills (36.3\%). Injectables accounted for less than two per cent of total episodes (Table 1). The median duration (in months) of a method used was the highest for IUD (12 months) followed by pills (9 months) and was the least for injectables.

The gross life table cumulative discontinuation rate of the selected modern contraceptive methods due to method failure and side effect and health concerns is presented in Table 2. The discontinuation rate due to method failure within 12 months of use was highest for male condoms (3\%) and was lowest among IUD users (1.2\%). On the contrary, the discontinuation rate due to side effect or health concern within 12 months of use was highest for injectables (14.7\%) and lowest for male condoms (3\%). The magnitude of discontinuation rate of all the selected methods was higher for discontinuation due to side effects as compared to method failure. However, discontinuation due to side effect as well as method failure for male condom was consistent (3\%). The probability of discontinuation of the contraceptive method due to method failure and side effect was higher for all the contraceptive methods with an increased duration of its use (Figure 1 and 2). Until 24 months, the probability of discontinuing injectables because of method failure was higher compared to pills. However, after 24 months, this was reversed, the probability of discontinuing pills due to method failure was higher as compared to injectables. On the contrary, the probability of discontinuation due to side effect or health concern was higher for injectables until 36 months as well as until 54 months of use (Figure 2). The probability of discontinuation due to side effect was low for the male condom.

\section{Life-table net discontinuation rate by background characteristics}

Table 3 presents the life table net discontinuation rate of the selected modern contraceptive method due to method failure and side effects or health concerns by selected socio-economic and demographic characteristics of women. In general, the magnitude of discontinuation due to side effects for all methods was higher than discontinuation due to method failure. With an increase in age of the women, the discontinuation rate due to method failure first increased then decreased for pills and IUD users. However, the discontinuation rate declined consistently among male condom users and a U-shape curve was observed for injectable users. For example, the discontinuation rate of pills due to method failure was $2.8 \%$ among $15-24$ years aged women, which increased to $3.4 \%$ among $25-34$ years aged and 3\% among 35-49 years women. Conversely, the discontinuation rate of injectables was $3.9 \%$ among $15-24$ years, $2.2 \%$ among $25-34$ years and $2.7 \%$ among 35-49 years. Whereas, in general, the discontinuation rate due to side effects or health concerns increased with the advancement in age except for injectables which showed a U-shaped curve.

The discontinuation rate due to method failure and side effects was higher in urban areas than in rural areas except for injectables and male condoms. Women from the Sikh community reported the highest discontinuation rate due to side effects for all kinds of methods. The discontinuation rate was highest among women from the poorest quintile due to method failure, whereas it was highest among women from the richest quintile due to side effects. The discontinuation rate due to method failure increased with an increase in the parity of the women. However, this was not so for discontinuation due to side effects. The discontinuation rate due to method failure and a side effect of all selected methods was higher among women using a method to limit birth compared to those using birth spacing. For example, 'the pill users' iscontinuation rate due to method failure was $3.1 \%$ for spacing and $11.5 \%$ for limiting.

\section{Survival hazard ratio of contraceptive discontinuation}

Table 4 presents the survival hazard ratio of discontinuation of a contraceptive method using the competing risk regression model by specific reasons of discontinuation. As compared to women using the IUD method, the survival hazard ratio of discontinuation was higher among women using other selected methods, for 
both method failure as well as side effects except for condom, which showed higher hazard for method failure $(\mathrm{SHR}=3.24)$ but lower hazard ratio for side effects $(\mathrm{SHR}=0.31)$. The women using pills had 2.35 times and 1.6 times higher hazard of discontinuation of pills due to method failure and side effect, respectively, compared to women using IUD. With an increase in age, the hazard of discontinuation of the method significantly declined due to method failure.

Women from the Muslim community had a higher hazard of discontinuing a method due to method failure ( $\mathrm{SHR}=1.16)$ but a lower hazard due to side effects
( $\mathrm{SRH}=0.86)$. The survival hazard ratio of discontinuation due to both reasons were higher among women using a contraceptive method for limiting birth compared to birth spacing ( $\mathrm{SHR}=2.76$ for method failure versus $\mathrm{SHR}=1.40$ for side effects). The survival hazard ratio of discontinuation of a method due to method failure increased with increased parity of the women. In general, the difference in hazard ratio of discontinuation of the contraceptive method due to method failure and the side effect was insignificant for place of residence, caste, educational status and wealth quintile.

Table 1: Percent distribution and median duration of number of contraceptive episodes use among married women aged 15-49 years, India, NFHS-4 (2015-2016).

\begin{tabular}{|c|c|c|c|c|c|}
\hline \multirow{2}{*}{ Contraceptive method } & \multicolumn{3}{|c|}{ Number of episodes } & \multirow{2}{*}{$\begin{array}{l}\text { Median duration of use } \\
\text { (in months) }\end{array}$} & \multirow{2}{*}{ Total } \\
\hline & 1 & 2 & $3+$ & & \\
\hline Pill & 65.9 & 24.9 & 9.2 & 9 & 34097 \\
\hline IUD & 84.7 & 11.8 & 3.5 & 12 & 11190 \\
\hline Injectable & 80.4 & 14.7 & 4.9 & 6 & 1722 \\
\hline Male condom & 61.6 & 26.7 & 11.8 & 7 & 46893 \\
\hline
\end{tabular}

Table 2: Discontinuation rate by reason for discontinuation among married women aged 15-49 years who experienced an episode of contraceptive use within the five years preceding the survey, India, (2015-2016).

\begin{tabular}{|c|c|c|c|c|c|c|c|c|c|c|c|}
\hline \multirow[b]{2}{*}{$\begin{array}{l}\text { Contraceptive } \\
\text { method }\end{array}$} & \multicolumn{5}{|c|}{ Method failure (in months) } & \multicolumn{5}{|c|}{ Side effects/health concerns ${ }^{\mathrm{a}}$ (in months) } & \multirow{2}{*}{$\begin{array}{l}\text { Number } \\
\text { of } \\
\text { episodes } \\
\text { of use }^{b}\end{array}$} \\
\hline & 12 & 24 & 36 & 48 & 60 & 12 & 24 & 36 & 48 & 60 & \\
\hline Pill & 1.9 & 2.9 & 3.4 & 4.2 & 5.0 & 11.1 & 15.8 & 18.3 & 20.6 & 23.8 & 34097 \\
\hline IUD & 1.2 & 1.8 & 2.2 & 2.8 & 2.8 & 9.1 & 13.6 & 18.3 & 20.9 & 25.0 & 11190 \\
\hline Injectables & 2.1 & 3.1 & 3.2 & 3.6 & 3.6 & 14.7 & 16.8 & 18.1 & 18.8 & 26.8 & 1722 \\
\hline Male condom & 3.0 & 4.5 & 5.2 & 6.0 & 6.9 & 3.0 & 3.9 & 4.3 & 4.6 & 5.1 & 46893 \\
\hline
\end{tabular}

Figures are based on life table calculations using the information on episodes of contraceptive use that began 3-62 months preceding the survey. All methods exclude female and male sterilisations; IUD=intrauterine device; reasons for discontinuation are mutually exclusive; aincludes side effects/health concerns, created menstrual problem, and gained weight; ${ }^{\mathrm{b}}$ number of episodes of use includes both episodes of use that were discontinued during the period of observation and episodes of use that were not discontinued during the period of observation.

Table 3: Discontinuation rates of contraceptive methods by reasons for discontinuation among women by selected background characteristics, India, 2015-2016.

\begin{tabular}{|llllllllll|}
\hline $\begin{array}{l}\text { Background } \\
\text { characteristics }\end{array}$ & Pill & IUD & Injectables & $\begin{array}{l}\text { Male } \\
\text { condom }\end{array}$ & Pill & IUD & Injectables & $\begin{array}{l}\text { Male } \\
\text { condom }\end{array}$ \\
\hline Total & 3.2 & 1.8 & 2.6 & 4.4 & 16.1 & 14.4 & 15.9 & 3.6 \\
\hline Age (in years) & & & & & & & & & \\
\hline $15-24$ & 2.8 & 1.8 & 3.9 & 4.6 & 11.2 & 11.0 & 16.0 & 2.4 \\
\hline $25-34$ & 3.4 & 2.2 & 2.2 & 4.5 & 15.6 & 13.5 & 15.4 & 3.5 \\
\hline $35-49$ & 3.0 & 0.9 & 2.7 & 3.4 & 24.8 & 20.4 & 16.7 & 6.3 \\
\hline Parity & & & & & & & & 16.1 & \\
\hline $0-1$ & 2.2 & 1.3 & 2.3 & 3.5 & 13.6 & 14.6 & 3.0 \\
\hline $2-3$ & 3.2 & 1.5 & 2.5 & 4.3 & 16.1 & 14.6 & 18.3 & 4.1 \\
\hline $4+$ & 5.5 & 6.0 & 3.2 & 7.5 & 15.7 & 16.0 & 10.9 & 3.6 \\
\hline
\end{tabular}




\begin{tabular}{|c|c|c|c|c|c|c|c|c|}
\hline \multirow[b]{2}{*}{$\begin{array}{l}\text { Background } \\
\text { characteristics }\end{array}$} & \multicolumn{4}{|c|}{ Method failure } & \multicolumn{4}{|c|}{ Side effects/health concerns } \\
\hline & Pill & IUD & Injectables & $\begin{array}{l}\text { Male } \\
\text { condom }\end{array}$ & Pill & IUD & Injectables & $\begin{array}{l}\text { Male } \\
\text { condom }\end{array}$ \\
\hline \multicolumn{9}{|c|}{ Women's education } \\
\hline No education & 4.1 & 5.2 & 1.5 & 6.3 & 14.1 & 15.2 & 12.2 & 3.4 \\
\hline Primary & 3.7 & 3.2 & 3.6 & 5.6 & 16.5 & 11.8 & 13.0 & 3.6 \\
\hline Secondary & 2.9 & 1.2 & 4.0 & 3.9 & 15.7 & 14.8 & 15.7 & 3.8 \\
\hline Higher secondary & 1.8 & 1.3 & 0.2 & 3.7 & 21.9 & 14.1 & 21.8 & 3.3 \\
\hline \multicolumn{9}{|c|}{ Mass media exposure } \\
\hline Yes & 2.7 & 1.2 & 2.3 & 3.9 & 17.7 & 15.0 & 16.6 & 3.7 \\
\hline No & 4.0 & 4.2 & 3.7 & 6.1 & 13.3 & 12.1 & 13.7 & 3.3 \\
\hline \multicolumn{9}{|c|}{ Contraceptive intent } \\
\hline Spacer & 3.1 & 1.9 & 2.5 & 4.4 & 11.0 & 11.2 & 14.6 & 2.6 \\
\hline Limiter & 11.5 & 2.8 & 12.1 & 15.0 & 14.9 & 12.7 & 16.7 & 3.9 \\
\hline \multicolumn{9}{|l|}{ Religion } \\
\hline Hindu & 3.2 & 1.9 & 3.0 & 3.9 & 16.5 & 13.6 & 15.5 & 3.6 \\
\hline Muslim & 3.5 & 1.9 & 1.9 & 6.5 & 12.0 & 14.5 & 12.8 & 2.7 \\
\hline Christian & 1.4 & 1.3 & 0.3 & 3.6 & 19.6 & 9.3 & 22.2 & 4.2 \\
\hline Sikh & 1.6 & 0.3 & 3.3 & 3.3 & 43.2 & 22.1 & 35.4 & 6.8 \\
\hline Others & 1.8 & 4.8 & 0.0 & 8.4 & 16.4 & 22.0 & 39.4 & 2.5 \\
\hline \multicolumn{9}{|l|}{ Caste } \\
\hline Scheduled caste & 3.1 & 1.4 & 4.0 & 4.7 & 16.4 & 14.2 & 11.5 & 3.7 \\
\hline Scheduled tribe & 2.6 & 1.4 & 4.2 & 3.1 & 14.9 & 15.3 & 14.8 & 3.9 \\
\hline OBC & 3.4 & 2.6 & 2.4 & 4.4 & 16.3 & 12.4 & 15.8 & 3.3 \\
\hline Other & 3.3 & 1.4 & 2.0 & 4.3 & 17.3 & 17.5 & 17.7 & 3.8 \\
\hline \multicolumn{9}{|c|}{ Household wealth quintile } \\
\hline Poorest & 3.5 & 3.3 & 2.4 & 4.7 & 12.4 & 11.5 & 10.9 & 3.7 \\
\hline Poorer & 3.2 & 1.4 & 4.8 & 5.1 & 13.9 & 12.8 & 15.0 & 2.9 \\
\hline Middle & 3.1 & 3.2 & 1.2 & 4.9 & 15.8 & 14.4 & 14.0 & 3.3 \\
\hline Richer & 2.7 & 1.3 & 2.6 & 3.8 & 17.6 & 13.4 & 15.0 & 3.5 \\
\hline Richest & 3.2 & 1.6 & 2.3 & 4.1 & 22.9 & 16.0 & 20.5 & 4.0 \\
\hline \multicolumn{9}{|l|}{ Place of residence } \\
\hline Rural & 3.0 & 1.4 & 2.4 & 3.8 & 14.7 & 14.4 & 16.4 & 3.7 \\
\hline Urban & 3.7 & 2.3 & 2.9 & 5.0 & 19.3 & 14.5 & 15.2 & 3.5 \\
\hline \multicolumn{9}{|l|}{ Region } \\
\hline North & 2.3 & 0.7 & 3.8 & 3.3 & 24.0 & 15.9 & 14.0 & 4.5 \\
\hline Central & 5.7 & 1.6 & 1.8 & 5.9 & 15.5 & 15.0 & 14.8 & 2.7 \\
\hline East & 2.8 & 2.4 & 3.1 & 3.0 & 16.2 & 12.8 & 15.0 & 3.7 \\
\hline North-East & 2.2 & 0.5 & 2.5 & 1.3 & 10.2 & 9.2 & 14.3 & 2.5 \\
\hline West & 5.8 & 4.7 & 3.5 & 6.4 & 14.6 & 15.4 & 20.5 & 3.6 \\
\hline South & 0.8 & 0.5 & 0.0 & 0.8 & 14.9 & 13.1 & 19.2 & 3.7 \\
\hline
\end{tabular}

Discontinuation rates has been calculated using information on episodes of contraceptive method use that began 3-62 months preceding the survey.

Table 4: Cause-specific survival hazard ratio of factors associated with reason for contraceptive discontinuation by selected background characteristics, India, 2015-2016.

\begin{tabular}{|lll|}
\hline Background characteristics & \multicolumn{2}{l|}{ Reasons for discontinuation } \\
\cline { 2 - 3 } & Method failure & Side effect/health concern \\
\hline Contraceptive method & & \\
\hline IUD & & 1.00 \\
\hline Pill & 1.00 & $1.59^{* *}$ \\
\hline Injectables & $2.35^{* *}$ & $1.81^{* *}$ \\
\hline Condom & $1.92^{* *}$ & $0.31^{* *}$ \\
\hline Age (in years) & $3.24^{* *}$ & \\
\hline $15-24^{\circledR}$ & & 1.00 \\
\hline
\end{tabular}

Continued. 


\begin{tabular}{|c|c|c|}
\hline \multirow{2}{*}{ Background characteristics } & \multicolumn{2}{|c|}{ Reasons for discontinuation } \\
\hline & Method failure & Side effect/health concern \\
\hline 25-34 & $0.54 * *$ & 0.94 \\
\hline $35-49$ & $0.32 * *$ & 0.90 \\
\hline \multicolumn{3}{|l|}{ Parity } \\
\hline $0-1^{\circledR}$ & 1.00 & 1.00 \\
\hline $2-3$ & $1.70 * *$ & 1.05 \\
\hline $4+$ & $2.62 * *$ & 1.10 \\
\hline \multicolumn{3}{|l|}{ Women's education } \\
\hline No education ${ }^{\circledR}$ & 1.00 & 1.00 \\
\hline Primary & 1.02 & 1.09 \\
\hline Secondary & 0.96 & $1.19 * *$ \\
\hline Higher secondary & 1.06 & 1.09 \\
\hline \multicolumn{3}{|l|}{ Contraceptive intention } \\
\hline Spacing $^{\circledR}$ & 1.00 & 1.00 \\
\hline Limiting & $2.76^{* *}$ & $1.40 * *$ \\
\hline \multicolumn{3}{|l|}{ Religion } \\
\hline $\operatorname{Hindu}^{\circledR}$ & 1.00 & 1.00 \\
\hline Muslim & $1.16^{*}$ & $0.86 * *$ \\
\hline Christian & 1.14 & $1.37 * *$ \\
\hline Sikh & $1.34 *$ & $1.80 * *$ \\
\hline Others & 0.95 & 1.04 \\
\hline \multicolumn{3}{|l|}{ Caste } \\
\hline Scheduled caste ${ }^{\circledR}$ & 1.00 & 1.00 \\
\hline Scheduled tribe & 0.97 & 1.04 \\
\hline Other backward class & 0.97 & 0.96 \\
\hline Other & 0.98 & 0.98 \\
\hline \multicolumn{3}{|l|}{ House hold wealth quintile } \\
\hline Poorest $^{\circledR}$ & 1.00 & 1.00 \\
\hline Poorer & 0.96 & 1.09 \\
\hline Middle & 0.93 & $1.13^{*}$ \\
\hline Richer & 0.90 & 1.07 \\
\hline Richest & 0.84 & 1.10 \\
\hline \multicolumn{3}{|l|}{ Place of residence } \\
\hline Urban $^{\circledR}$ & 1.00 & 1.00 \\
\hline Rural & 0.94 & 0.98 \\
\hline \multicolumn{3}{|l|}{ Region } \\
\hline North $^{\circledR}$ & 1.00 & 1.00 \\
\hline Central & $2.01 * *$ & $0.90^{*}$ \\
\hline East & $1.20 *$ & $0.76^{* *}$ \\
\hline North-East & 0.98 & $0.55 * *$ \\
\hline West & $2.02 * *$ & 0.88 \\
\hline South & 0.68 & $1.26 * *$ \\
\hline
\end{tabular}

${ }^{\oplus}$ reference category; the reference category for dependent variable for competing risk regression are the rest of the reasons for discontinuation other than the reason of interest; $* * \mathrm{p}<0.01,{ }^{*} \mathrm{p}<0.05$.

\section{DISCUSSION}

This study examined the modern contraception discontinuation among married women of reproductive age group in India, using reproductive calendar data by exploring the episodes of contraception use, discontinuation due to side effects and method failure. The contraceptive histories collected in the NFHS-4 provides a unique opportunity to examine an array of issues regarding contraceptive adoption. Most studies on contraception obtain information collected from a cross-sectional survey that can severely limit to capture the nuances in contraceptive behaviour. For instance, in these kinds of studies, the contraception prevalence rate was generally calculated based on two questions: ever used any method, and whether currently using any method, often with a reference period of 12 months preceding the survey. However, consistent use of reversible methods did not adequately reflect in a cross-sectional kind of survey design particularly, for a method that needed to be adopted 
during every sexual act, for example, condom. The present study filled this gap using contraceptive histories collected in NFHS and provides a unique opportunity in examining varied issues regarding contraceptive adoption.

The study found that the discontinuation rate of all selected methods was higher due to side effects than method failure. The survival hazard ratio of discontinuation due to both reasons was higher among women using the contraceptive method for limiting birth than birth spacing. Contraceptive methods that were most often discontinued due to side effects/health concerns were pill, IUD and injectables. Side effect or health concern was the leading cause for discontinuation among women using injectables.
Previous studies had documented that one of the major side effects of modern contraception use was menstrual periods irregularity, increased bleeding length and cramping. ${ }^{29,30}$ An earlier study also revealed that estrogen-related, dosedependent, nonlethal side effects are the principal healththreatening side effects of combined pills. ${ }^{31}$ The majority of IUD users discontinued due to prolonged and heavier bleeding. ${ }^{32}$ Moreover, discontinuation of injectables was also linked to the lack of awareness and counselling about its side effects. ${ }^{33}$ Methods with fewer or no side effects could lead to greater satisfaction of any method use resulting in higher contraceptive continuation and fewer unintended pregnancies and induced abortions.

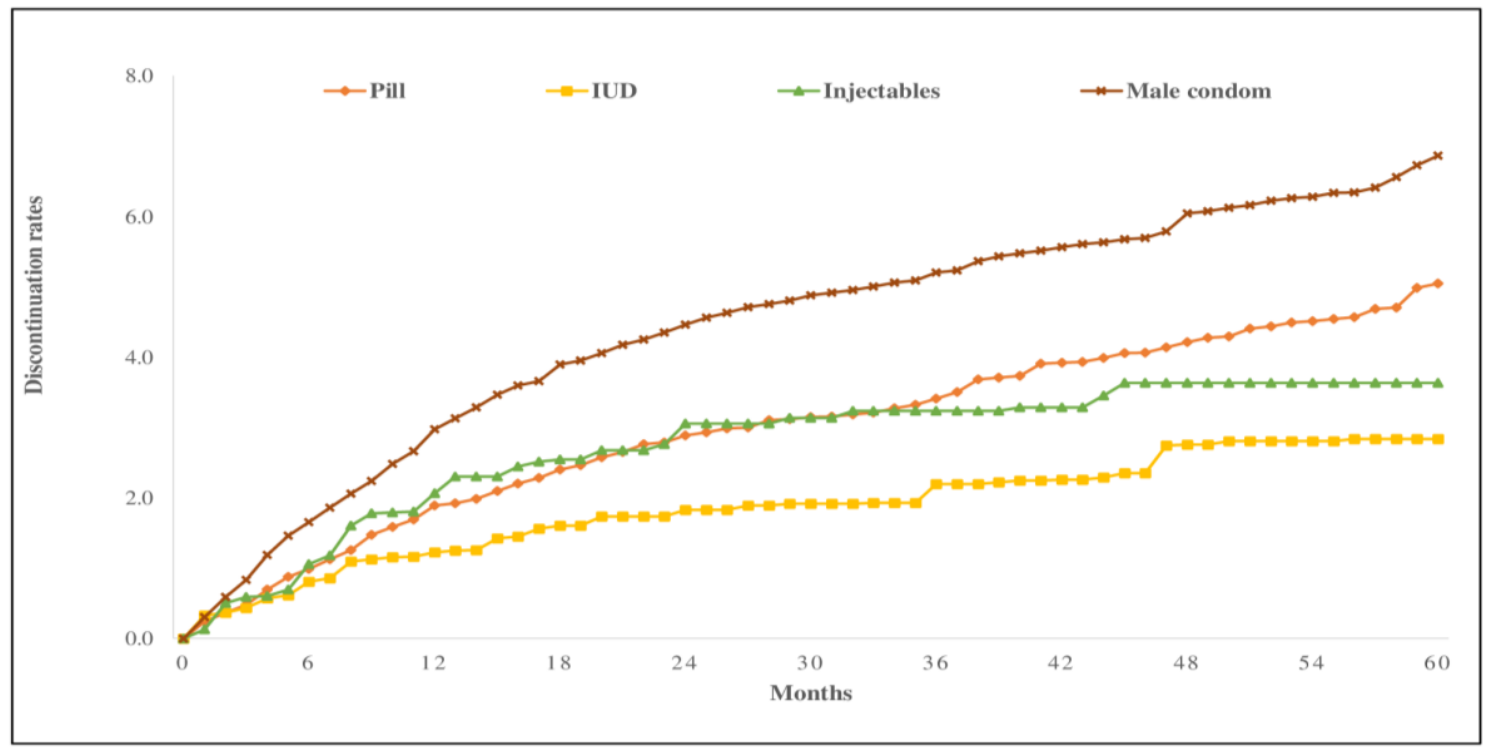

Figure 1: Cumulative life table discontinuation rates for selected reversible methods due to method failure among married women aged 15-49 years, India, 2010-2016.

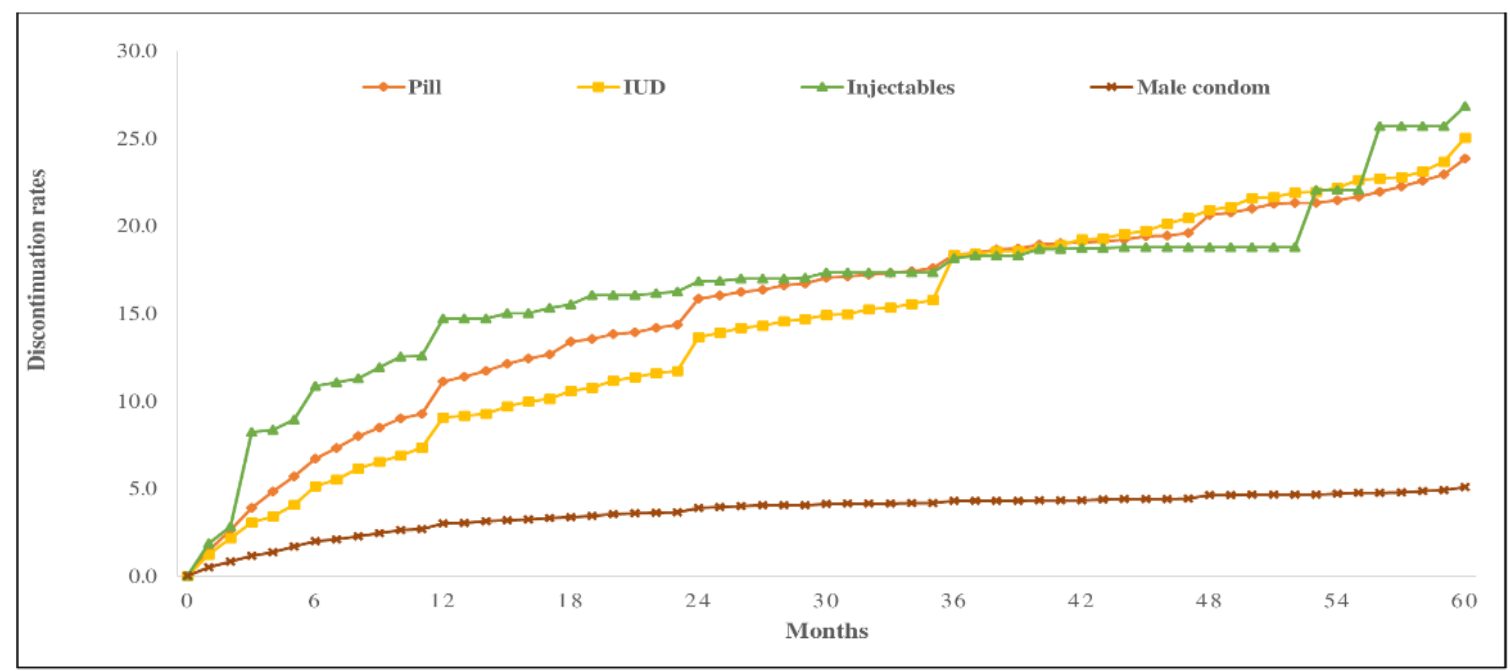

Figure 2: Cumulative life table discontinuation rates for reversible methods due to side effects/health concerns among married women aged 15-49 years, India, 2010-2016. 
Method failure was one of the important reasons for contraceptive discontinuation and often led to unintended pregnancies. Evidence indicated that method failure accounted for about 16 per cent of unintended births, ranging from as low as 2 per cent in Benin to as high as 41 per cent in Bangladesh. ${ }^{19}$ The discontinuation rate due to method failure was the highest for male condoms and the lowest for IUD. This study documented that 5 per cent of pill users and 6 per cent of condom users discontinued due to method failure (60 months episode). The higher contribution of method failure can be attributed to lower effectiveness compared to their theoretical effectiveness. This was likely an indication that adequate counselling was necessary to ensure that methods were used correctly and consistently. Evidence also suggested that oral contraceptives discontinuation due to failure was quite common and male condoms failure was often due to incorrect use. $^{34}$ Another possible reason for discontinuation of pills could be non-compliance. ${ }^{35}$ A past study demonstrated that a fieldworker's enthusiastic attitude towards oral contraceptives (OCs) and discussion about cycles of pills was found to have a positive role in the continuation of OC use. ${ }^{36}$

Contraceptive use behaviour is an important determinant of fertility with considerable socio-economic and demographic implications and contraception discontinuation due to method failure can significantly increase unintended pregnancies affecting the women and a country as a whole to stabilise population growth. High rates of contraceptive discontinuation was a negative influencer for any family planning programs and undermine their ability to protect women from unwanted pregnancies. $^{23}$ Therefore, a study on contraceptive discontinuation had significant programmatic implications especially given that in India, over 10 per cent of women in the reproductive age group have an unmet need for contraception with considerable variation across the socioeconomic groups.

The study's strengths were that the findings were based on a very large number of women surveyed in a nationally representative survey with a robust sampling design. The study documented the pattern and predictors of contraceptive discontinuation using the calendar data and the results can be helpful for strengthening family planning policy and program. The high rates of discontinuation stress the need to improve service quality and counselling so that women can be informed about informed choices and forewarned about possible side-effects and health concerns. Given the high discontinuation rate of many contraceptive methods and the frequency of contraceptive failure, suggesting inconsistent or incorrect use, strategies to promote improved contraceptive use following method selection are essential. ${ }^{1,37,38}$

\section{Limitations}

The current study had a couple of limitations. Female and male sterilisation cases were excluded from the analyses, which might have excluded a few cases from the analysis who might be using any method even after their husband was sterilised. Further, during the discontinuation analyses, early entry, late entry and women using any method throughout the calendar period were censored, resulting in the exclusion of few women whose partners might be using a male condom to avoid sexually transmitted diseases. Since the respondents were asked about their contraceptive history for the last five years, there was a likelihood of recall bias resulting in under or over-reporting of contraceptive methods used. Furthermore, the current analysis was based on the crosssectional survey and hence the causality cannot be established and only shows the relationship of discontinuation with the selected socio-economic background of the women.

\section{CONCLUSION}

The discontinuation rate of all selected methods was higher due to side effects than method failure. The high discontinuation rate of many contraceptive methods and the frequency of contraceptive failure suggest the need for strategies to promote improved contraceptive use following method selection. Improved quality of services through proper counselling of the potential contraceptive users would enhance informed choice, thus increasing modern contraception continuation among women in India.

\section{Funding: No funding sources \\ Conflict of interest: None declared \\ Ethical approval: The study was approved by the Institutional Ethics Committee}

\section{REFERENCES}

1. Jain AK. Fertility reduction and the quality of family planning services. Stud Fam Plann. 1989;20(1):1-16.

2. Bruce J. Fundamental elements of the quality of care: a simple framework. Stud Fam Plann. 1990;21(2):61-91.

3. Jain AK, Hardee K. Revising the FP quality of care framework in the context of rights-based family planning. Stud Fam Plann. 2018;49(2):171-9.

4. United Nations. Levels and Trends of Contraceptive Use as Assessed in 2002. New York, 2006. Accessed on 23 June 2021. Available at: https://www.un.org/en/development/desa/population/pu blications/pdf/family/worldContraceptiveUseReport200 2.pdf. Accessed on 10 June 2021.

5. United Nation Department of Economic and Social Affairs Population Divison. Trends in contraceptive use worldwide 2015. New York, 2015. Epub ahead of print 2015. Available

at: https://www.un.org/development/desa/pd/sites/www.un. org.development.desa.pd/files/undesa_pd_report_2015_ trends_contraceptive_use.pdf. Accessed on 20 June 2021.

6. RamaRao S, Lacuseta M, Costello M, Pangolibay B, Jones H. The link between quality of care and 
contraceptive use. Int Fam Plan Perspect. 2003;29(2):7683.

7. Steele F, Curtis SL, Choe M. The impact of family planning service provision on contraceptive-use dynamics in Morocco. Stud Fam Plann. 1999;30(1):2842.

8. Koenig MA, Foo GHC, Joshi K. Quality of care within the Indian family welfare programme: A review of recent evidence. Stud Fam Plann. 2000;31(1):1-18.

9. Bertrand J, Magnani RJ, Rutenberg N. Handbook of indicators for family planning program evaluation. North Carolina: US Aid; 1994.

10. Blanc AK, Curtis S, Croft T. Does contraceptive discontinuation matter? Quality of care and fertility consequences. North Carolina: US Aid; 1999.

11. Jain A, Bruce J, Mensch B. Setting standards of quality in family planning programs. Stud Fam Plann. 1992;23:392-5.

12. Vaughan B, Trussell J, Kost K, Singh S, Jones R. Discontinuation and resumption of contraceptive use: results from the 2002 National survey of family growth. Contraception. 2008;78(4):271-83.

13. Trussell J. Contraceptive failure in the United States. Contraception. 2011;83(5):397-404.

14. Curtis S, Evens E, Sambisa W. Contraceptive discontinuation and unintended pregnancy : an imperfect relationship. Int Perspect Sex Reprod Health. 2011;37(2):58-66.

15. Unintended Pregnancies in the Middle East and North Africa. Washington D.C., 2010. Epub ahead of print 2010. Available at: https://www.prb.org/resources/unintended-pregnanciesin-the-middle-east-and-north-africa/. Accessed on 20 June 2021.

16. Casterline JB, El-Zanaty F, El-Zeini LO. Unmet need and unintended fertility: longitudinal evidence from upper Egypt. Int Fam Plan Perspect. 2003;29(4):158-66.

17. Blanc AK, Curtis SL, Croft TN. Monitoring contraceptive continuation: links to fertility outcomes and quality of care. Stud Fam Plann. 2002;33(2):127-40.

18. Finer LB, Henshaw SK. Disparities in rates of unintended pregnancy in the United States, 1994 and 2001. Perspect Sex Reprod Health. 2006;38(2):90-6.

19. Jain AK, Winfrey W. Contribution of contraceptive discontinuation to unintended births in 36 developing countries. Stud Fam Plann. 2017;48(3):269-78.

20. Jain A. Should eliminating unment need for contraception continue to be a programme priority. Int Fam Plan Perspect. 1999;25:39-43.

21. Cleland J, Ali MM. Reproductive consequences of contraceptive failure in 19 developing countries. Obstet Gynecol. 2004;104(2):314-20.

22. Pariani S, Heer DM, Arsdol MD. Does choice make a difference to contraceptive use? Evidence from East Java. Stud Fam Plann. 1991;22(6):384-90.

23. Cotten N, Stanback J, Maidouka H. Early discontinuation of contraceptive use in Niger and The Gambia. Int Fam Plan Perspect. 1992;18:145-9.
24. Ali M, Cleland J. Contraceptive discontinuation in six developing countries: a cause-specific analysis. Int Fam Plan Perspect. 1995;21(3):92.

25. International Institite for Population Sciences (IIPS), ICF. National Family Health Survey (NFHS-4) 2015-16 India. $2017 . \quad$ Available at: http://rchiips.org/NFHS/NFHS-4Reports/India.pdf. Accessed on 10 June 2021.

26. DHS. DHS Contraceptive Calendar Tutorial. North Carolina: US Aid; 2018: 4-48.

27. Satagopan JM, Ben-Porat L, Berwick M, Robson M, Kutler D, Auerbach AD. A note on competing risks in survival data analysis. Br J Cancer. 2004;91(7):1229-35.

28. Fine JP, Gray RJ. A proportional hazards model for the subdistribution of a competing risk a proportional hazards model for the sub distribution of a competing risk. J Am Stat Assoc. 1999;94(446):496-509.

29. Sharma M, Joshi S, Nagar O. Determinants of intrauterine contraceptive device discontinuation among Indian women. J Obstet Gynecol India. 2014;64:208-11.

30. Adal TG. Early discontinuation of long acting reversible contraceptives among married and in union women : a systematic review and meta-analysis. Ann Med Health Sci Res. 2017;7:113-8.

31. Vitzthum VJ, Ringheim K. Hormonal contraception and physiology: a research-based theory of discontinuation due to side effects. Stud Fam Plann. 2005;36(1):13-32.

32. Tolley E, Loza S, Kafafi L, Cummings S. The impact of menstrual side effects on contraceptive discontinuation: findings from a longitudinal study in Cairo, Egypt. Int Fam Plan Perspect. 2005;31(1):15-23.

33. Population Council. Fact sheet: Injectable Contraceptives: Perspectives and experiences of women and health care providers in India, 2012. Available at: https://knowledgecommons.popcouncil.org/. Accessed on 23 June 2021.

34. Westhoff CL, Heartwell S, Edwards S, Zieman M, Stuart G, Cwiak C, et al. Oral contraceptive discontinuation: do side effects matter? Am J Obstet Gynecol. 2007;196(4):412.

35. Dehlendorf C, Krajewski C, Borrero S. Contraceptive counseling: best practices to ensure quality communication and enable effective contraceptive use. Clin Obstet Gynecol. 2014;57(4):659-73.

36. Khan MA. Factors associated with oral contraceptive discontinuation in rural Bangladesh. Health Policy Plan. 2003;18(1):101-8.

37. Mensch B, Arends-Kuenning M, Jain A. The impact of the quality of family planning services on contraceptive use in Peru. Stud Fam Plann. 1996;27(2):59-75.

38. RamaRao S, Mohanam R. The quality of family planning programs: concepts, measurements, interventions, and effects. Stud Fam Plann. 2003;34(4):227-48.

Cite this article as: Shete MR, Kumar P, Anand E, Singh J, Pradhan MR. Discontinuation of modern contraception methods due to side effects and method failure in India: an analysis using reproductive calendar data. Int J Reprod Contracept Obstet Gynecol 2021;10:3462-71. 